\title{
Influence of platinum ions on phenolic compounds in Lepidium sativum seedlings
}

\author{
Monika Czaja, Anna Kołton, Piotr Muras \\ University of Agriculture in Krakow, Faculty of Biotechnology and Horticulture; al. 29 Listopada 54, 31-425 Krakow, Poland; \\ e-mail:mon.czaja@gmail.com,a.kolton@ogr.ar.krakow.pl,romuras@cyf-kr.edu.pl
}

(C) 2014 Authors. This is an open access publication, which can be used, distributed and reproduced in any medium according to the Creative Commons CC-BY 4.0 License requiring that the original work has been properly cited.

Received: 30 November 2014; accepted: 23 December 2014

\begin{abstract}
Despite limiting the transport emitted pollution, contamination of the roadside environment remains an important issue. Due to necessity to decrease the lead emission, catalytic converters modifications were introduced. It caused increase of Platinum Group Elements (PGEs) emission, which was rare in the environment before. So far there is lack of information about platinum contamination to functioning of plants which are so important in the urban environment.

In the experiment garden cress (Lepidium sativum) were sown into Petri dishes filled with filter paper soaked with solutions of different platinum concentration. There were used two compounds containing platinum at different oxidation states $\mathrm{PtCl}_{4}$ - solutions containing 0.58, 2.89, 5.79, 11.58 and $23.16 \mathrm{mg} \mathrm{Pt}^{4+} \cdot \mathrm{dm}^{-3}$ and $\left[\mathrm{Pt}\left(\mathrm{NH}_{3}\right)_{4}\right]$ $\left(\mathrm{NO}_{3}\right)_{2}$ - solutions containing $0.50,2.52,5.04,10.08$ and $20.15 \mathrm{mg} \mathrm{Pt}^{2+} \cdot \mathrm{dm}^{-3}$ in every combination of the experiment. In every combination there were five Petri dishes, experiment was repeated twice. To estimate plant response to stress factor, phenolic compounds contents were analyzed in the roots and shoots parts separately.

The highest amount of total phenolics in roots was recorded in plants treated with highest $\mathrm{Pt}^{4+}$ dose which was $23.16 \mathrm{mg} \cdot \mathrm{dm}^{-3}$, seeds treated with other doses of platinum (including those treated with highest dose of $\mathrm{Pt}^{2+}$ ) did not differ significantly from control plants.

In the case of phenolic compounds in the aboveground parts of seedlings there was highest accumulation than in roots. Highest amounts of phenolics were recorded in plants also treated with $\mathrm{Pt}^{4+}$ in doses 11.58 and $23.16 \mathrm{mg} \cdot \mathrm{dm}^{-3}$.
\end{abstract}

Keywords: Lepidium sativum, heavy metals, $\mathrm{Pt}^{4+}, \mathrm{Pt}^{2+}$, oxidative stress

\section{INTRODUCTION}

Plants are exposed to different anthropogenic environmental pollution. They uptake various ions from soil during growth. These ions can be essential to the growth but also harmful. The heavy metal ions are most dangerous to plant functioning. They cause reduction of growth rate, disrupt functioning of photosynthesis and transpiration due to structural damage of leaves. Also root functioning is affected by heavy metal uptake, which can cause disorder in water and nutrient uptake (Ovečka \& Takáč 2014). Heavy metal accumulation in plant growth environment causes oxidative stress. That kind of stress leads to disruption of many growth and developmental processes. Plants developed some defense mechanisms to oppose stress induced by Reactive Oxygen Species (ROS). They are based on enzymatic antioxidants such as peroxidase, catalase, superoxide dismutase and others, or on low molecular weight antioxidants such as phenolic compounds, ascorbic acid and others (Bhaduri \& Fulekar 2012). Phenolic compounds are one of the most important groups of metabolites involved in the antioxidative defense. They are divided by the chemical structure to simple 
phenols, benzoic acids, phenylopropanoids and flavonoids. The induction of phenolic compounds synthesis is observed during heavy metal stress. Phenolics show high capacity to chelate metals, inhibit lipid peroxidation by trapping lipid alkoxyl radical, and stabilize membranes by decreasing membrane fluidity. High amounts of phenolics are found in the roots of plants exposed to heavy metal ions (Michalak 2006). In the recent years new problem in the anthropogenic contamination became Platinum Group Elements (PGEs) which contain mainly platinum, palladium, rhodium and ruthenium. PGEs are the main components of the modern fuel catalyst. Due to usage of elements from this group in the engine engineering, emission of road traffic pollutant decreased. Leakage of the PGE becomes a new environmental issue. It is proven that metals from this group interfere to the environment and can accumulate in the living organisms' tissues (Sobrova et al. 2012). In the study conducted on grass growing along roads, Hooda et al. (2007) proved that platinum is accumulated in investigated plant tissues, and the total platinum concentration in soil was correlated with its concentration in tissues. Most of conducted studies concern the case when the PGEs are accumulated in plants or human cells, but there is still lack of information about plant reactions to this kind of pollution in their growth environment. The aim of the study was to investigate the phenolic compounds content in roots and shoots parts of garden cress plants treated with platinum ions $\left(\mathrm{Pt}^{2+}, \mathrm{Pt}^{4+}\right)$.

\section{METHODS}

\section{Plant material}

Seeds of garden cress (Lepidium sativum) were sowed into Petri dishes soaked with solutions of different platinum concentration. There were used two compounds containing platinum at different oxidation states $\mathrm{PtCl}_{4}$ - solutions containing $0.58,2.89,5.79,11.58$ and $23.16 \mathrm{mg} \mathrm{Pt}^{4+} \cdot \mathrm{dm}^{-3}$ and $\left[\mathrm{Pt}\left(\mathrm{NH}_{3}\right)_{4}\right]\left(\mathrm{NO}_{3}\right)_{2}$ - solutions containing 0.50, 2.52, 5.04, 10.08 and $20.15 \mathrm{mg} \mathrm{Pt}{ }^{2+} \cdot \mathrm{dm}^{-3}$ in every combination of the experiment. Control plants were sown into Petri dishes with distilled water. In every combination there were five dishes, experiment was repeated twice. Plants were germinated for 48 hours in darkness in the incubator and then were moved under the white LED lamps for another 48 hours.

\section{Analysis of phenolic compounds}

The factor phenolics compounds were investigated to establish the plants reaction to the stress. Analyses were held separately in the above ground parts and in the roots. Phenolic compounds were analyzed after sample homogenization in $80 \%$ methanol, centrifugation and dilution with $0.1 \% \mathrm{HCl}$ in $96 \%$ ethanol and $2 \% \mathrm{HCl}$ in $\mathrm{H}_{2} \mathrm{O}$. Spectrophotometric measurements were done at 280, 320 and $360 \mathrm{~nm}$ wavelengths, according to Fukumoto \& Mazza (2000). Standards used to estimate particular phenolics amount were respectively, chlorogenic acid for total phenolic content, quercitin for flavonols and caffeic acid for phenylpropanoids. For every combination phenolic compounds were analyzed in six duplications.

\section{Statistical analysis}

Data were analyzed by analysis of variance (ANOVA). Standard deviations were designated and presented as plus/minus error bars. The significance of differences were determined according to the LSD-Fisher tests, with significance $\alpha=0.05$ [Statistica 10, Statsoft]. Values marked on the figures with the same letters belong to the same statistical group.

\section{RESULTS}

In the experiment, we proved influence of platinum ions to the phenolic compounds content both in the roots and aboveground parts of garden cress seedlings.

Total phenolic content in the aboveground parts of garden cress was the lowest in the plants treated with the $2.52 \mathrm{mg} \cdot \mathrm{dm}^{-3}$ of $\mathrm{Pt}^{2+}$ but did not differ significantly from $0.5 \mathrm{mg} \cdot \mathrm{dm}^{-3}$ and $10.08 \mathrm{mg} \cdot \mathrm{dm}^{-3}$ doses and also from $2.89 \mathrm{mg} \cdot \mathrm{dm}^{-3}$ of $\mathrm{Pt}^{4+}$ (Fig. 1). High values of total phenolic content was noted in the plants treated with 23.16 and $11.58 \mathrm{mg} \cdot \mathrm{dm}^{-3}$ of $\mathrm{Pt}^{4+}$ but did not differ significantly from those treated with 5.79 and $0.58 \mathrm{mg} \cdot \mathrm{dm}^{-3}$ of $\mathrm{Pt}^{4+}$ and also 5.04 and $20.15 \mathrm{mg} \cdot \mathrm{dm}^{-3}$ of $\mathrm{Pt}^{2+}$. Only plants treated with 23.16 and $11.58 \mathrm{mg} \cdot \mathrm{dm}^{-3}$ of $\mathrm{Pt}^{4+}$ showed significantly highest values of total phenolic compounds in compare to control. Plants treated with $2.52 \mathrm{mg} \cdot \mathrm{dm}^{-3}$ of $^{\mathrm{Pt}^{2+}}$ showed 
significantly lower content of total phenolics than controlled ones.

In the case of flavonols, seeds treated with any doses of platinum did not differ significantly from the control plants (Fig. 2).
Phenylpropanoids content was the lowest in the plants treated with $2.52 \mathrm{mg} \cdot \mathrm{dm}^{-3}$ of $^{\mathrm{Pt}^{2+}}$ and the highest in the plants treated with $5.79 \mathrm{mg} \cdot \mathrm{dm}^{-3}$ of $\mathrm{Pt}^{4+}$ but none of the investigated cases differ significantly from control (Fig. 3).

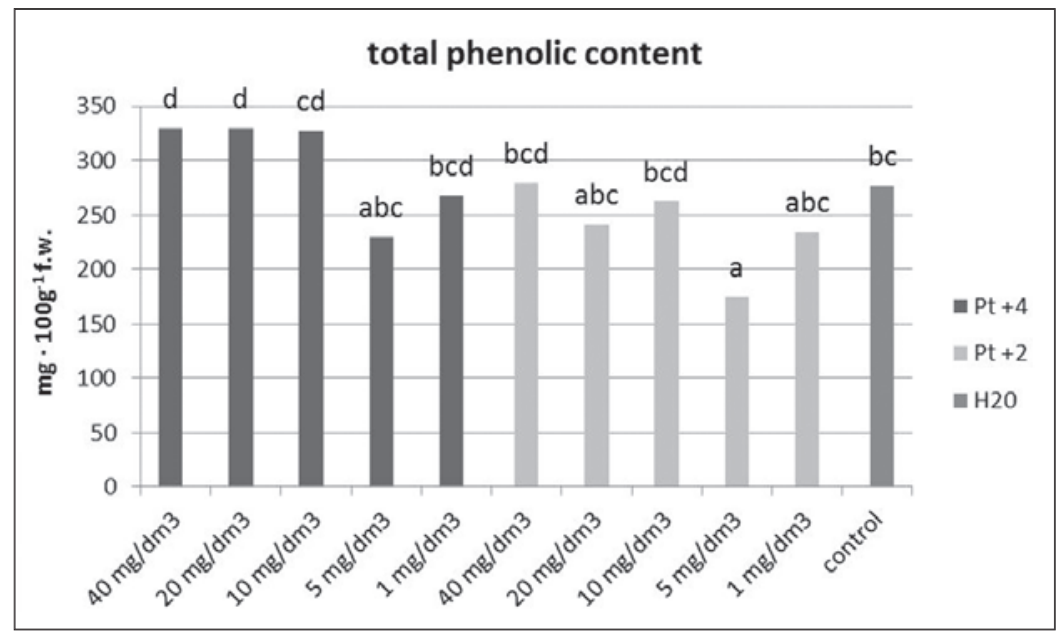

Fig. 1. Total phenolic content in the aboveground parts of investigated plants

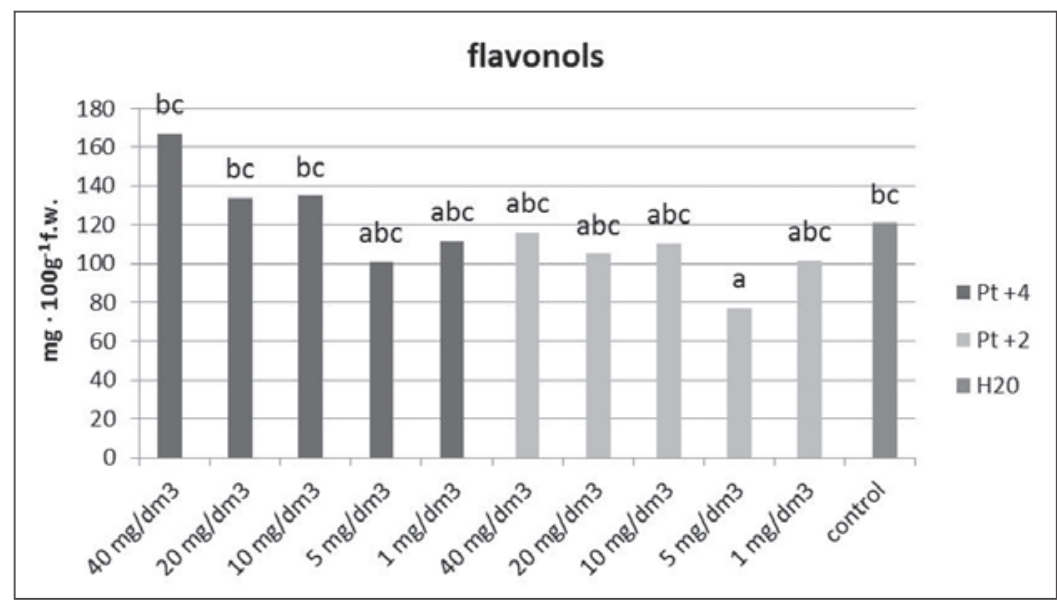

Fig. 2. Flavonols content in the aboveground parts of investigated plants

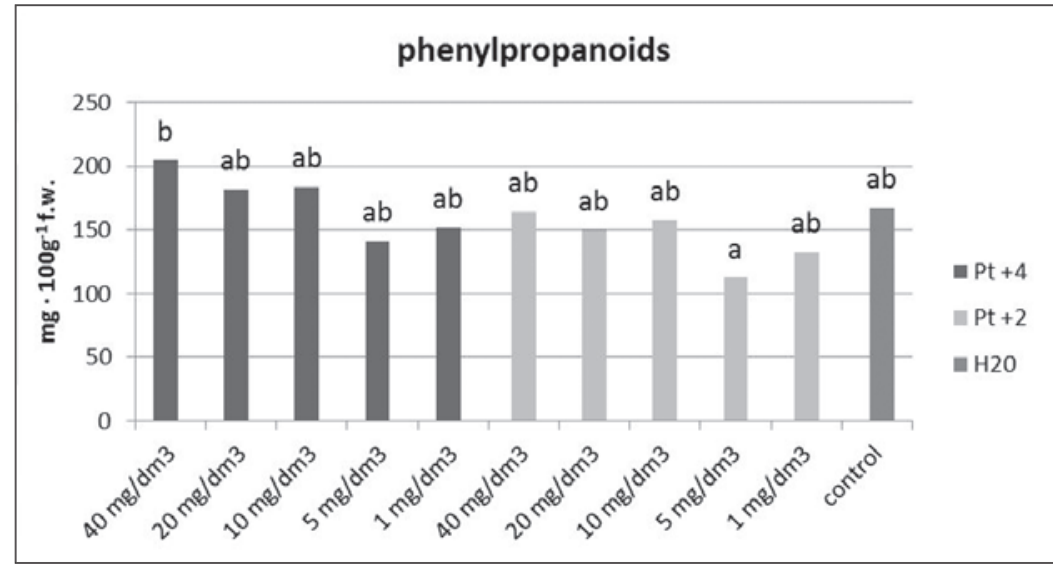

Fig. 3. Phenylpropanoids content in the aboveground parts of investigated plants 


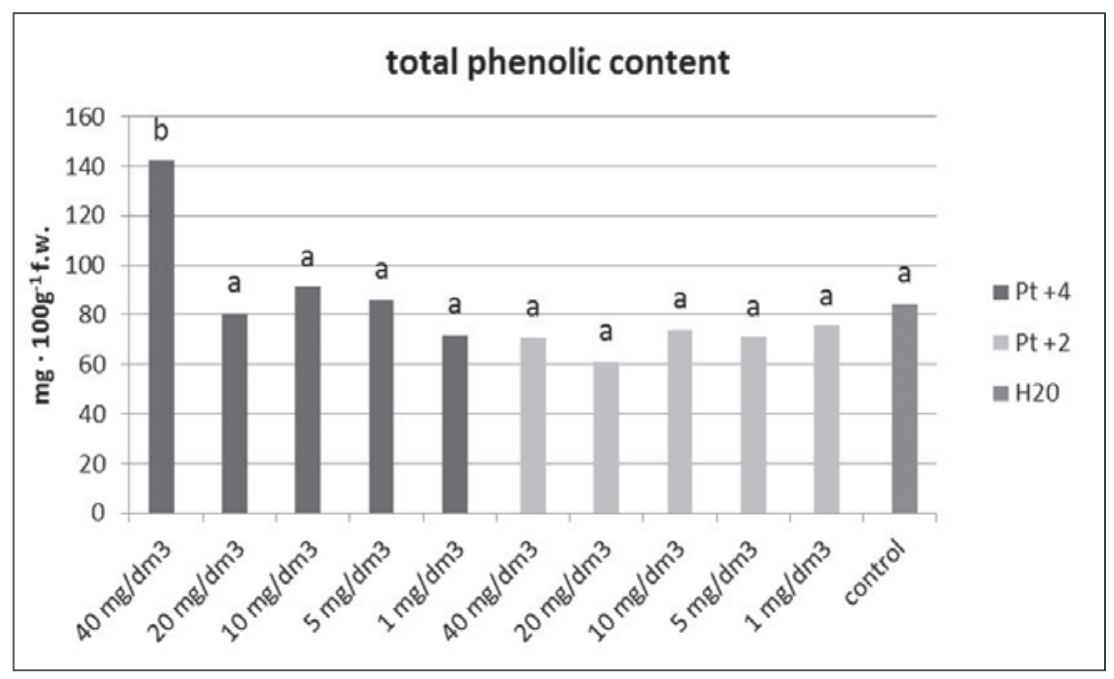

Fig. 4. Total phenolic content in the roots of investigated plants

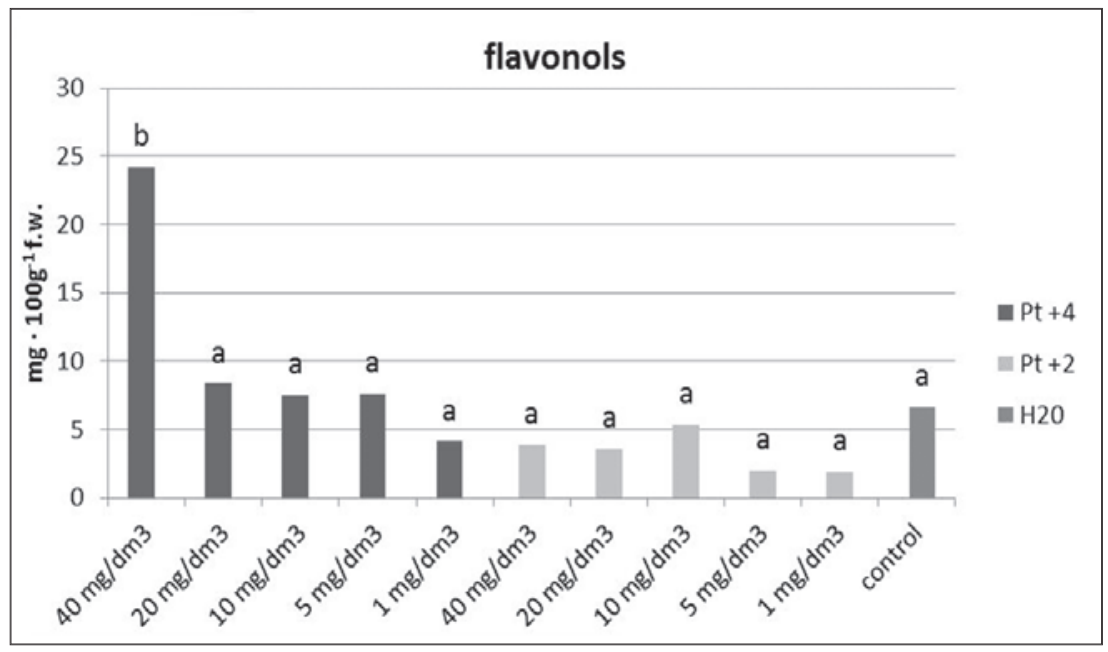

Fig. 5. Flavonols content in the roots of investigated plants

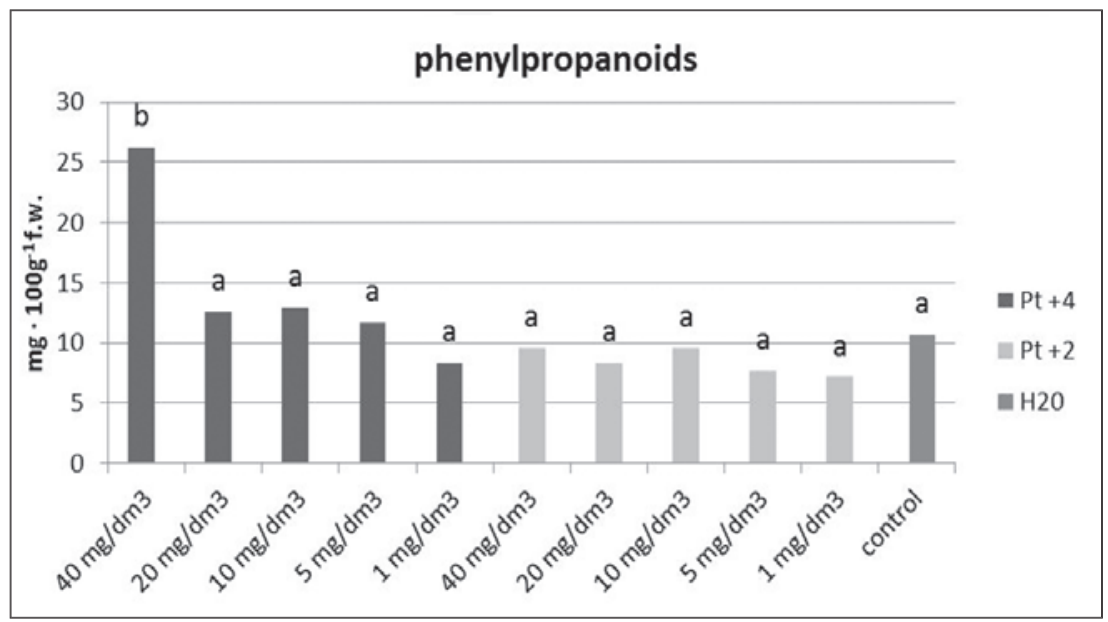

Fig. 6. Phenylpropanoids content in the roots of investigated plants 
Total phenolic content, flavonols and phenylpropanoids content in the roots was the highest in plants treated with $23.16 \mathrm{mg} \cdot \mathrm{dm}^{-3}$ of $\mathrm{Pt}^{4+}$, seeds treated with other doses did not differ significantly from the control plants (Figs 4-6).

\section{DISCUSSION}

Heavy metals present in the environment even in trace amounts can induce stress reactions in plants. Unfavorable conditions disrupt ROS production, which formation and removal are controlled in normal conditions. Under stress, ROS are overproduced, which in consequence leads to oxidative stress. Plants exhibit different mechanisms of coping with that kind of these mechanisms are strongly related to the metal type and also plant species. Opposing oxidative stress is based on enzymatic defense (activation enzymes like peroxidase, catalase and superoxide dismutase) or non-enzymatic including increased phenolic compounds production (Mourato et al. 2012). It is difficult to find researches about phenolic compounds in plants treated with platinum, although it is known that different heavy metal stress influence phenolic compounds production. In the studies on Lycopersicon esculentum and Spinacea oleracea seeds, increased amounts of copper $(\mathrm{Cu})$ and lead $(\mathrm{Pb})$ in the growing solution, resulted in phenolic compounds increase (Hameed et al. 2001). Also studies carried on Verbascum thapsus proved, that increased amount of zinc $(\mathrm{Zn})$ in the growing solution was connected with phenolic compounds increase. Growth of phenolic content precedes growth disruption and cell death both in leaves and roots. The same experiment showed also that roots and leaves developed different antioxidative mechanisms (Morina et al. 2008). Seedlings of Helianthus annuus treated with exceeded values of manganese $(\mathrm{Mn})$ showed increased production of phenolic compounds as well (Torabi \& Khavarinejad 2014). In presented studies on garden cress, $\mathrm{Pt}^{4+}$ at doses 11.58 and $23.16 \mathrm{mg} \cdot \mathrm{dm}^{-3}$ of used compound caused increase of total phenolic content in the aboveground parts in compare to control plants. In the case of roots, $\mathrm{Pt}^{4+}$ at dose $23.16 \mathrm{mg} \cdot \mathrm{dm}^{-3}$ of used compound caused increase of total phenolics, flavonoids and phenylpropanoids in compare to roots of control plants. Other doses of $\mathrm{Pt}^{4+}$ and $\mathrm{Pt}^{2+}$ in any dose of compound had not influence on significant increase of phenolics production in compare to control. What is interesting, solution containing $\mathrm{Pt}^{4+}$ induced phenolic compound production, while solution containing $\mathrm{Pt}^{2+}$ considered as more toxic did not cause that kind of reaction. The highest used doses of $\mathrm{Pt}^{2+}$ did not cause phenolics increase as a plant reaction to oxidative stress. Such reaction might be caused not only by oxidation state of used ions but also by additional anions present in the solutions (Bae et al. 2014). Lepidium is known to be highly sensitive to metal toxicity, and is widely used in the biological tests (Janecka \& Fijalkowski 2008). It can be considered as a good indicator also in estimating platinum influence on plants. Although to get a wider view on the platinum toxicity issue, experiment should be repeated with higher doses of used compounds and with other plants.

Study was supported by Polish Ministry of Science and Higher Education DS 3500/2014.

Authors are grateful to Grażyna Sierant for excellent technical support.

\section{REFERENCES}

Bae J., Mercier G., Watson A.K. \& Benoit D.L., 2014. Seed germination test for heavy metal phytotoxicity assessment. Canadian Journal of Plant Science, 94, 15191521.

Bhaduri A.M. \& Fulekar M.H., 2012. Antioxidant enzyme responses of plants to heavy metal stress. Reviews in Environmental Science and Biotechnology, 11, 1, 55-69.

Fukumoto L. \& Mazza G., 2000. Assesssing antioxidant and prooxidant activities of phenolic compounds. Journal of Agricultural and Food Chemistry, 48, 8, 3597-3604.

Hameed N., Siddiqui Z.S. \& Ahmed S., 2001. Effects of Copper and Lead on Germination, Accumulation and Phenolic Contents of Spinancea oleracea and Lycopersicum esculentum. Pakistan Journal of Biological Sciences, 4, 7, 809-811.

Hooda P.S., Miller A. \& Edwards A.C., 2007. The distribution of automobile catalysts-cast platinum, palladium and rhodium in soils adjacent to roads and their uptake by grass. Science of the Total Environment, 384, 1-3, 384-392.

Janecka B. \& Fijalkowski K., 2008. Using Lepidium as a test of phytotoxicity from lead/zinc spoils and soil conditioners. [in:] Simeonov L. \& Sargsyan V. (eds), Soil Chemical Pollution, Risk Assessment, Remediation and Security, NATO Science for Peace and Security, Springer Science+Business Media B.V., Dordrecht, 177-182. 
Michalak A., 2006. Phenolic Compounds and Their Antioxidant Activity in Plants Growing under Heavy Metal Stress. Polish Journal of Environmental Studies, 15, 4, 523-530.

Morina F. Jovanović L., Kukavica B. \& Veljović-Jovanović S., 2008. Peroxidase, phenolics and antioxidative capacity of common mullein (Verbascum thapsus) grown in a zinc excess. Archives of Biological Sciences Belgrade, 60, 4, 687-695.

Mourato M., Reis R. \& Louro Martins L., 2012. Characterization of Plant Antioxidative System in Response to Abiotic Stresses: A Focus on Heavy Metal Toxicity. [in:] Montanaro G. \& Dichio B. (eds),
Advances in Selected Plant Physiology Aspects, InTech, $24-44$.

Ovečka M. \& Takáč T., 2014. Managing heavy metal toxicity stress in plants: Biological and biotechnological tools. Biotechnology Advances, 32, 1, 73-86.

Sobrova P., Zehnalek J., Adam V., Beklova M. \& Kizek R., 2012. The effects on soil/water/plant/animal systems by platinum group elements. Central European Journal of Chemistry, 10, 5, 1369-1382.

Torabi S. \& Khavarinejad R.A., 2014. Effects of manganese toxicity on activation of antioxidant enzymes, Anthocyanin and total phenolic content in Sunflower (Helianthus annuus L.). Annals of Biological Science 2, 3, 42-47. 